\title{
Proximization Theory and the Construction of International Values: A Case Study of President Xi Jinping's Speech at the 70th Session of the UN General Assembly
}

\author{
Yunyou Wang \\ Department of International Studies, Southwest University, Chongqing, China
}

\begin{abstract}
Under the cognitive linguistics approach to CDS (Critical Discourse Study), this paper selects the construal operation of "deixis" and takes Chinese President Xi Jinping's speech at the 70th session of the United Nations General Assembly as a corpus in order to examine through the cognitive-pragmatic model of proximization theory how this text delivers the international value of "a community of shared future for mankind." The three dimensions of "spatial proximization," "temporal proximization," and "axiological proximization" serve as analytical tools for evaluating discourse strategies in political discourse and the shaping of international values with Chinese characteristics. The study shows that proximization theory could be well suited to critical discourse analysis and its spatial-temporal-axiological (STA) model possess the specific explanatory power in value construction.
\end{abstract}

Index Terms - cognitive linguistic approach to CDS, proximization theory, a community of shared future for mankind, construal operation, international value

\section{INTRODUCTION}

On January 18, 2017, Chinese President Xi Jinping attended a high-level meeting at the United Nations Office in Geneva. Here, he delivered a keynote speech titled "Work Together to Build a Community of Shared Future for Mankind," and the concept of "a community of shared future for mankind" has since been officially included in the UN resolution adopted by the Security Council ${ }^{1}$.

President Xi followed this with his report to 19th Communist Party of China National Congress on Oct 18, 2017, where he proposed to "follow a path of peaceful development and work to build a community with a shared future for mankind." With the inclusion of "a community with a shared future for mankind" into the Communist Party constitution, this concept again attracted attention within the international community and triggered extensive research by scholars in China and abroad. Currently, most of the domestic discourse on "building a community of shared future for mankind" revolves around the domestic and foreign environment of public opinion from the perspective of political science and communication, just like discourses on power and identity. For example, Zhou $(2018)^{2}$ discusses the significance of "building a community of shared future for mankind" in securing China's greater influence regarding strengthening the right of expression. Guo (2017) analyzes the construction process of China's global governance through the discourse practice of "Chinese solutions" from the perspective of communication, then summarizes the construction of the basic idea of Chinese solutions in global governance using the concept of "a community with shared future for mankind."

However, the discourse on "a community of shared future for mankind" has been only rarely examined from the perspective of linguistic theory, which in particular offers the approaches of systemic functional linguistics and social functional linguistics. Q. Wen (2017) analyzes the concept of "a community with shared future for mankind" from the UN speech through interpersonal and textual functions of the metaphor. Huang (2017) uses systemic functional grammar to examine the speech from the angle of functional discourse analysis, revealing its register and genre characteristics. Hong Zhang (2017) takes the speech as a corpus to apply the theory of sociocultural linguistics, discussing how to build national image through discourse.

Cognitive linguistics reveals the relationship between language, concept, and the human mind. As a concept, "a community with a shared future for mankind" aims to spread itself globally and exert its influence on the audience. Through the cognitive mechanism of the human mind, we can explain how the speaker (the communicator of a concept) manipulates discourse strategies during the communication process. Critical discourse analysis of the underlying ideology and the primitive and final status of ontology can then be examined, so as to explore whether the discourse

\footnotetext{
1 In the Resolution 2344 (2017) adopted by the UN Security Council at its 7902nd meeting, on 17 March 2017, "a community of shared future for mankind" is firstly mentioned.

${ }^{2}$ Throughout the main text and references, Chinese names are represented in the traditional "Western" order of given name followed by family name. A first initial or full given name is included to disambiguate scholars with the same family name.
} 
strategies used allow the concept of "a community with a shared future for mankind" to spread effectively.

On the basis of research outcomes from combining critical discourse analysis (CDA) with cognitive linguistics (Hui Zhang and Jiang, 2008; Tian 2013; T. Zhang and Guo 2016), this paper applies proximization theory within the "deixis" construal operation as its analytical tool, using President Xi's speech at the 70th session of the General Assembly as a corpus, to demonstrate the effectiveness of the spread of the international value of "a community with a shared future for mankind." At the same time, this paper attempts to faithfully convey the intention behind the idea, thus enriching the discourse study of international value from the perspective of linguistics.

\section{DEIXIS AND PROXIMIZATION}

The construal operation is a core concept of cognitive grammar in cognitive linguistics. This operation aims to explain why people have different ways of expressing the same event. At the same time, as an important cognitive mode the construal operation determines the corresponding language expression; this can be used to discuss how and what kind of differences people experience when they perceive the same event (X. Wen, 2011). As an important part of the construal operation, deixis involves the use of conceptualization to explain the meaning construction of parts beyond the sentences in discourse, and adopts a practical positioning method to illustrate the consistency of textual context and subjective values.

As a newly developed concept in linguistics, "proximization" offers a concrete analytical tool for interpreting the deixis construal operation. The concept of "proximizing," which simply means bringing closer, originates from the political discourse research of Paul Chilton. Chilton (2004) believes that discourse - that is, language in use-is a process whereby readers and hearers set up discourse worlds (conceptual domains" or "ontological spaces") that carry a deictic "signature" for space, time, and modality, and relationships among them (p. 138). Cap (2006) develops Chilton's view and coins the term "proximization". In its most general and practical sense, proximization is a discursive strategy of presenting physically and temporally distant events and states of affairs (including "distant adversarial ideologies") as increasingly and negatively consequential to the speaker and the addressee (Cap, 2013, p. 293). The speaker can use various means to highlight that the distant entities are gradually encroaching upon the speaker and addressee geographically and ideologically, but the primary goal is to legitimize the speaker's own actions and policies-evoking the closeness of the external threat and soliciting the legitimization of preventive measures. The threat comes from entities peripheral to the discourse space, referred to as "outside-deictic-center" entities (ODCs), which are conceptualized as crossing the space to invade "inside-deictic-center" entities (IDCs) - the speaker and the addressee. The threat possesses both a spatial-temporal and ideological nature that sanctions the division of proximization into three aspects. (Cap, 2014). In Cap's proximization theory, an ODC has a temporal, spatial, and axiological nature, the three aspects of the proximization model. When entities and events are mapped onto axes representing social space, time, and ideological distance, mental space provides conceptual coherence to the context and an analytical tool with which to reveal and evaluate the ideologies conveyed in the discourse.

In recent years, proximization theory has been applied to the analysis of state political discourses, providing a research path and analysis tool for discourse construction including crisis construction and war rhetoric, immigration discourse analysis, party representation, and national memory construction.

\section{Proximization Theory And the Shaping of International VAlues in “A COMmunity of ShaRed Future FOR MANKIND"}

Since its inception, the concept of "a community of shared future for mankind" has been welcomed by international society for its comprehensive and systematic elaboration of China's vision of global governance. At the 55th session of UN Commission for Social Development, the commission elected to include "to create a shared future, based upon our common humanity" into the UN Economic and Social Council resolution for the first time ${ }^{3}$. The UN Security Council subsequently did the same. This immediate acceptance from international bodies demonstrates that "building a community of shared future for mankind" is in-line with the interests and aspirations of people from countries around the world, and widely recognized by UN member states. This demonstrates China's contribution to global governance.

President Xi's speech "Work Together to Build a Community of Shared Future for Mankind" is 2992 words long, and divided into three parts. The first part describes the development history of the international community, briefly recalling the background of the founding of the United Nations 70 years ago, China's contribution to the world anti-fascist war ${ }^{4}$, and China's proper attitude towards history. The second part deals with the common challenges of mankind and the major issues facing the United Nations. The third discusses the concept of global governance, puts forward the Chinese solution to work together to build a community of shared future for mankind, and announces China's role in this effort and its action planning.

An important role of language is to represent the state of things (Chilton, 2004, p. 29). A speaker can legitimize his

\footnotetext{
3 In resolution adopted by the UN Economic and Social Council on 8 June 2017, the initial form of the concept "a community of shared future for mankind" , which was demonstrated as " to create a shared future, based upon our common humanity" is mentioned for the first time, and later it was officially written into the Resolution 2344 (2017)adopted by the UN Security Council.

4 The anti-fascism war refers to the Word War II.
} 
position by choosing a way of speaking that conforms to the speaker's own interests to describe objective things, and create a durable common cognition by constructing a universal experience with which the addressee can identify. This cognition will lead the addressee to form certain beliefs about reality and to recognize certain actions in the future. These elements of speech, in particular time, location, and ideology held by the speaker, are important in building a common cognition.

The structure of President Xi's speech demonstrates that the international values of "a community of shared future for mankind" are constructed primarily around three topics: the development of the international community, the problems facing mankind, and the concept of global governance. In the process of constructing these topics, the text relating to "a community of shared future for mankind" reflects the process of constructing common cognition through spatial, temporal, and axiological language strategies as well as their combination.

\section{A. Development of an International Community and Temporal Proximization}

Temporal proximization can be used as a method of enhancing spatial proximization. In the spatial axis, temporal proximization is useful for interpreting a process wherein an event is approaching or has already occurred. According to Cap (2013), temporal proximization is a symbolic "compression" of the time axis, and a partial conflation of time frames, involving two simultaneous conceptual shifts (p.85-86). They are past-to-present shift and future-to-present shift. The past-to-present could construal the past events and actions, mainly those instigated/performed by the ODC entities, informing the speaker's present context, in the interest of her own current actions. And the information is validated by analogies holding between the past and the present context arrangements. The future-to-present shift accommodate construals of the near future ODC actions stemming directly from the present context, a collection of premises up-dated by the premises construed from the past events.

Under future-to-present shift, a future event is interpreted as entailing urgent need to take immediate measures; under past-to-present shift, past events are construed as still occurring and affecting reality. The first part of President Xi's speech, focusing on the developmental history of the international community, contains language strategies of temporal proximization.

The relationship between language and human history can be explained from the perspective of cognitive construction. Both thought and language are meaningful and can be interpreted as a reconstruction process that is propagated in a particular way. First, the role of language in memory structure cannot be ignored. It is not only a tool to understand the past, but also a way to reshape history. Through discourse characterization, the collective memory of history is formed, and the legitimization of historical behaviors and events is realized. President $\mathrm{Xi}$ opens his speech with a survey of the broad strokes the conflict that led to cooperation in the $20^{\text {th }}$ century as follows:

(1) Over the past century and more, mankind has gone through bloody hot wars and the chilling Cold War, but also achieved remarkable development and huge progress. In the first half of last century, mankind suffered the scourges of two world wars, and the people yearned for the end of war and the advent of peace. In the 1950s and 1960s, people in colonies awakened and fought to shake off shackles and achieve independence. Since the end of the Cold War, people have pursued a shared aspiration, namely, to expand cooperation and promote common development. ${ }^{5}$

This is a typical analogy strategy proximization. The speech begins with several important historical points: "in the first half of the last century," "in the 1950s and 1960s," and "since the end of the Cold War." At the same time, it describes the primary conflict events in international history: the two World Wars and the Cold War. The speech highlights the history of sovereign states seeking independence and the international community pursuing peaceful development after the sufferings of war. Although the positions and interests of countries in the war were different, reflection on the war must nonetheless be absolutely consistent-only peace can lead to development. With this timeline as the beginning of the speech, the speaker has made full use of the analogy strategy in the process of temporal proximization by contrasting the war with reality, finding resonance in and drawing lessons from this period, and so refreshing the addressees' collective historical memory of the misfortune brought by war.

The description of historical events can not only reconstruct collective agreement on the identity of different groups and connect their common concerns on practical issues, but also become a means to guide future actions. See the quotation from President Xi's Speech as follows:

(2) Peace and development: this has been the aspiration held dear by mankind over the past century. However, the goal to achieve peace and development is far from being met. We need to respond to the people's call, take up the baton of history and forge ahead on the marathon track toward peace and development.

The first sentence of this passage is an assertion based on history, for which we should "take the baton of history" and "forge ahead on the marathon track." Unlike the past-oriented strategy of the previous excerpt, this passage aims to shape common identity by using the future-oriented strategy to create a shared common space in which the international community can take action to inherit and extend the spirit of peace and development.

Memory therefore has a dual effect. On one hand, it helps to establish a collective memory of the past; on the other, it legitimizes or delegitimizes historical events to help people of different groups reconstruct these historical events and

\footnotetext{
5 The speech is written in Chinese, and translated into and published in English by Xinhua News Agency in its official website Xinhuanet.com/english. Xinhua News Agency is the official state-run press agency and a ministry-level institution subordinate to the Chinese central government. All the examples in the paper is extracted from the speech.
} 
shape a common identity.

\section{B. Spatial Proximization and "the Common Challenges Facing Mankind"}

Spatial proximization refers to the forced construal of the discourse space to perceive that peripheral entities are encroaching physically upon the discourse space of central entities, the speaker and addressee (Cap, 2013). While temporal proximization is synchronic, spatial proximization has a diachronic nature.

The second part of President Xi's speech describes the common challenges faced by mankind, such as terrorism, climate change, and economic recovery, as well as major issues currently facing the United Nations. In this discourse, the common challenges faced by human beings are frequently portrayed as metaphors about "hostile entities," and the speech applies the construal operation of spatial proximization to prompt the addressees to adopt some preventive "war" in response. Through this shaping of an inclusive international value, the addressees are persuaded to believe in their ability to prevent negative consequences.

On one hand, spatial proximization can be viewed as the most basic tool for legitimizing. In political interventionist discourses, a pre-emptive response to "collective threats" is legitimized by allowing the collective to perceive that a threat is imminent and will have a negative impact on individuals. Let's see the longer quotation from Xi's speech as follows:

(3) Terrorist attacks that have occurred in Europe, North Africa and the Middle East in recent years once again demonstrate that terrorism is the common enemy of mankind. Fighting terrorism is the shared responsibility of all countries. In fighting terror, we should not just treat the symptoms, but remove its root causes. We should enhance coordination and build a global united front against terrorism so as to create an umbrella of security for people around the world. The number of refugees has hit a record high since the end of the Second World War. While tackling the crisis, we should also get to its roots. Why would anyone want to be displaced if they have a home to return to? UNHCR and the International Organization for Migration should act as the coordinator to mobilize the whole world to respond effectively to the refugee crisis.

The passage describes terrorism as "the common enemy of mankind." Thus, the international community should "create an umbrella of security for people around the world." By establishing that terrorism is the "hostile entity" and describing the refugee crisis since the Second World War through analogy proximization, the speaker leads addressees to be frightened of approaching terrorism and also of the combined threat of terrorism and the suffering caused by wars. In addition, the speech uses lexical and grammatical carriers of spatial proximization, like "Europe, North Africa and the Middle East," to make addressees feel that the spatial distance from a specific terrorist event might be narrowing and such a threat is therefore imminent. The listener can then adopt a common position with the speaker and take countermeasures in advance. At the same time, through offering the example of the efforts made by the two major international organizations UNHCR and IOM on immigration, this passage asserts to addressees that the refugee issue caused by terrorism has been unavoidable - succeeding despite the best efforts of powerful organizations - and has already become an international issue that can be addressed only if we "mobilize the whole world," further drawing the addressees closer to the issue.

While such a spatial proximization strategy is conducive to reducing the distance between IDCs and ODCs, it is not limited to revealing the negative impact of ODCs on IDCs. In addition to interpreting the state interventionism discourse, which is to legitimize the war against the threat, proximization theory can also characterize the discourse about the national demonstration effect from the positive aspects of critical discourse analysis.

President Xi then turns his speech towards a concrete example of China's response and an appeal to other organizations for comparable involvement:

(4) China has decided to provide an additional 200 million yuan of humanitarian assistance for refugees and the displaced of Syria. As terrorism and refugee crises are closely linked to geopolitical conflicts, resolving conflicts provides the fundamental solution to such problems. Parties directly involved should return to the negotiating table, and other parties should work to facilitate talks for peace, and we should all respect the role the UN plays as the main channel for mediation. Pandemic diseases such as bird flu, Ebola and Zika have sounded the alarm for international health security. The WHO should play a leadership role in strengthening epidemic monitoring and sharing of information, practices and technologies. The international community should step up support and assistance for public health in African countries and other developing countries.

From the perspective of positive discourse analysis, China's deed in the world such as "provide an additional 200 million yuan of humanitarian assistance for refugees and the displaced of Syria" in this speech can be regarded as an ODC that can bring a positive impact. China's provision of aid to Syrian refugees and victims through " 200 million yuan of humanitarian assistance" sets a good "model" and attracts addressees to the cause by supporting the credibility of the need. In other words, this action can be viewed as a kind of social force embodied in the text. Tamly's force-dynamic theory (1988) offers that there are two entities, the "agonist" and the "antagonist," of which the agonist is "the entity whose circumstance is at issue." Force-dynamic schemas arise from pressure and motion, and the social force relates to the "interpsychological force interaction between sentient entities." The antagonist exerts force against the agonist, which causes changes to the agonist. By applying this approach to proximization theory, the speaker can be

\footnotetext{
${ }^{6}$ It is quoted from the President Xi's speech
} 
viewed as the antagonist who through speech exerts force on the agonist, namely, the addressee, causing psychological changes to the addressee and therefore changing the distance between the IDC (addresses) and ODC (China). Moreover, at the end of the quotation, the fact that China calls for WHO and international community to take actions has indeed demonstrated China's views on the common challenges the world is facing, and at the same time has strengthened the perception of validity for China's approach and actions when facing the common challenges, thus further narrowing the distance between ODCs and IDCs.

\section{Global Governance and Axiological Proximization}

Axiological proximization refers to the mechanism through which the ODCs' value is derived, from both far and near. The values of IDCs and ODCs are interpreted as there being a growing conflict of consciousness between the two. The mechanism of axiological proximization involves the addressee's construal of a continuing ideological conflict that eventually materializes in a physical clash between the speaker/addressee and the audience (Cap, 2010).

International values are generally regarded as the embodiment of ideology. The construction of certain ideology relies largely on whom is to convey the ideology and how to describe and explain it - that is, how to seek shared values or promote the integration of values through external forces. At the same time, it is also important to choose which events or issues to describe, and this choice itself has an impact on the value orientation of these events.

The third part of President Xi's speech describes China's solution on global governance, which calls for concerted efforts to build the "community of shared future" and announces China's role and actions towards achieving it. The core of axiological proximization lies in bridging the ideological conflicts between ODCs and IDCs by materializing certain values of the ODCs into the IDCs. See the quotation as follows:

(5) Geneva invokes a special memory to us. In 1954, Premier Zhou Enlai led a Chinese delegation to the Geneva Conference, and worked with the Soviet Union, the United States, the United Kingdom and France to seek political settlement of the Korean issue and a ceasefire in Indo-China. This demonstrated China's desire for peace and contributed Chinese wisdom to world peace. Since 1971 when China regained its lawful seat in the UN and began to return to international agencies in Geneva, China has gradually involved itself in disarmament, trade, development, human rights and social issues, putting forth Chinese proposals for the resolution of major issues and the making of important rules. In recent years, China has taken an active part in dialogues and negotiations on the Iranian nuclear issue, the Syrian issue and other hotspot issues, giving Chinese input to their political settlement. China applied to the International Olympic Committee to host both the summer and winter Olympic and Paralympic Games, and we have won the bids. In addition, we have gained endorsement from the International Union for Conservation of Nature for over a dozen applications for world natural heritage sites as well as world cultural and natural heritage sites. All this has presented Chinese splendor to the world.

In this passage, China's developmental history in the United Nations is reviewed and summarized, and a large number of value-oriented terms are presented, such as invoking "a special memory to us," contributing "Chinese wisdom," "giving Chinese input to their political settlement," and presenting "Chinese splendor to the world"- - establishing a positive context for China's development in the United Nations. This passage also makes addressees recall the past 45 years since China resumed its legal seat in the United Nations, when it has actively participated in UN efforts in security, development, society, human rights, law, and arms control and disarmament. The timing of the speech also supports this, made at the event marking the 70th anniversary of the founding of the United Nations. China's announcement of a series of important measures to support the cause of the United Nations in this context pushes China's cooperation with the UN to new heights.

At the same time, proposing the concept of a community of shared future for mankind marks that China has abandoned such ideas as "Western exploitation of Chinese system" and the need to "catch up with the Western countries." ${ }^{7}$ China no longer dwells on which foreign country in the world is better than it, but instead emphasizes that all countries share the world. That is the essence of "a community of shared future for mankind." After the proposal was put forward, the Chinese government turned the concept to practice by improving exchanges and cooperation with other countries through the Belt and Road Initiative. ${ }^{8}$ This extends the international discourse span from a few hundred years in the modern age to more than 2,000 years, transcending the dispute between universal values and Chinese characteristics, advocating common values for mankind, deconstructing Western-centered theory, and reflecting the historical transformation of China from standing up to becoming wealthy to growing strong.

As such, the speech marked China's views on international issues and global governance on the international stage of the United Nations. On one hand, it was an opportunity for China could persuade addressees to strengthen their recognition of Chinese values; on the other, it legitimized China's approach to the concept of global governance.

\section{Application of Proximization Theory}

According to the spatial-temporal-axiological (STA) model in proximization theory, these three strategies are

\footnotetext{
7 These were common ideas in modern times when China needed to draw experience from the western countries.

${ }^{8}$ The Belt and Road Initiative (BRI), also known as the One Belt One Road (OBOR) or the Silk Road Economic Belt and the 21st-century Maritime Silk Road, is a development strategy adopted by the Chinese government involving infrastructure development and investments in 152 countries and international organizations in Europe, Asia, Middle East, Latin America and Africa
} 
conducive to continuously narrowing the distance between entities in the discourse space and influencing addressees. According to Cap (2013), one of the principles of proximization theory is that, although any application will likely contain all three strategies — spatial, temporal, and axiological — the degree of their expression in the discourse parallels their effectiveness in changing contexts.

Take the first point in the global governance section as an example: "We should stay committed to building a world of lasting peace through dialogue and consultation." The purpose of this speech is to express the principle of international cooperation, which is different from Western mainstream values, and to give China a say in the context of major changes in the international landscape. To achieve this goal, it is necessary to choose from a large number of terms to reflect different strategies, so as to help achieve the goal of legitimization. See the two quotations below:

(6) We should stay committed to building a world of lasting peace through dialogue and consultation. When countries enjoy peace, so will the world; when countries fight, the world suffers. From the Peloponnesian War in the fifth century $\mathrm{BC}$ to the two world wars and the Cold War that lasted more than four decades, we have drawn painful and profound lessons. "History, if not forgotten, can serve as a guide for the future." By establishing the United Nations, those before us won more than 70 years of relative peace for the world. What we need to do is to improve the mechanisms and means to more effectively resolve disputes, reduce tension and put an end to wars and conflicts.

(7) The Swiss writer and Nobel laureate, Hermann Hesse stressed the importance of serving "not war and destruction but peace and reconciliation". Countries should foster partnerships based on dialogue, non-confrontation and non-alliance. Major powers should respect each other's core interests and major concerns, keep their differences under control and build a new model of relations featuring non-conflict, non-confrontation, mutual respect and win-win cooperation. As long as we maintain communication and treat each other with sincerity, the "Thucydides trap" can be avoided. Big countries should treat smaller ones as equals instead of acting as a hegemon imposing their will on others. No country should open the Pandora's box by willfully waging wars or undermining the international rule of law. Nuclear weapons, the Sword of Damocles that hangs over mankind, should be completely prohibited and thoroughly destroyed over time to make the world free of nuclear weapons. Guided by the principle of peace, sovereignty, inclusiveness and shared governance, we should turn the deep sea, the polar regions, the outer space and the Internet into new frontiers for cooperation rather than a wrestling ground for competition.

The first quotation above starts with an example that highlights the temporal strategy: "From the Peloponnesian War in the fifth century BC to the two world wars and the Cold War that lasted more than four decades, we have drawn painful and profound lessons." By choosing major wars from both ancient and modern times, the speech demonstrates China's in-depth thinking on the issue of peace as it stands relative to the international trend of historical development. The passage, organized essentially as a timeline, makes the addressees recall devastating wars in the past in association with present concerns - while the wars have gone away, the threat could become a reality again at any time, and no nation should assume that it is safe.

Later, the speech quotes the words of Swiss writer Hermann Hesse, which leads to the need to pursue a new path of dialogue instead of confrontation and partnerships rather than alliances. In this shift, the speech transitions from a temporal to spatial strategy. "Open the Pandora's box" is a phrase referring to the possibility of causing a particular kind of disaster, while "Sword of Damocles" implies ever-present potential. These two familiar Western allusions are used here to explain that if the international community fails to respect the principle of peaceful coexistence and mutual benefit, then the international rule of law will disappear. The ODCs in the sentence would threaten every individual in the international community.

This part of the speech utilizes maxims of universal values to strengthen the attraction and credibility of the context. The ability to project or define political discourse generally reflects the political ability of the speaker (Dunmire, 2011), and here the context is endowed with the recognition of history, internationality, and justice.

At the same time, in order to highlight the negative impact of turbulent international relations and make it easier for addressees to accept the notion of relatively abstract international values, the speech employs metaphors to create conceptual scenes through which the symbolic movement of ODCs towards IDCs enhance the sense of threat to both speaker and addressees. To achieve this, most metaphors in this speech offer the location, speed, and negative effects of a threat entity, or the positive effects of successfully avoiding a threat. 
the frequency of different strategies used in different topics

\begin{tabular}{|c|c|c|c|}
\hline Dimension & Temp oral proximization & Spatial proximizaztion & Axiological proximization \\
\hline International social development & 6 & 4 & 4 \\
\hline $\begin{array}{c}\text { The conmon challenges facing } \\
\text { human beings }\end{array}$ & 4 & 7 & 8 \\
\hline $\begin{array}{l}\text { Global governance } \\
\text { (Chinese solutions) }\end{array}$ & 8 & 5 & 10 \\
\hline
\end{tabular}

To further illustrate the comprehensive use of STA model, we divide the speech into three parts according to the themes, and count down the frequency of different strategies utilized in every part as follow ${ }^{9}$ :

The above table shows that the three dimensions of proximization theory can be used to examine how the discourse of President Xi's speech achieves the ideological convergence of ODC and IDC by narrowing the temporal, spatial, and axiological distance between the two. In the process of shaping international values, the speaker makes full use of the mechanism of proximization theory, which is essentially a compensation mechanism (Cap, 2015). In each of the examples above, all three strategies of proximization theory are present. However, the actual degree of textual representation is driven by their effectiveness in changing contexts. Therefore, in order to ensure consistency with the overall purpose of discourse, the development of external context might lead the speaker to restrict the use of a strategy and achieve compensation through the others.

Theoretically, critical discourse analysis addresses the conceptual arrangement of discourse spaces, and especially the rearrangement of symbols in these spaces. As Cap (2014) describes, the central commitments of CDS include exploring the many ways in which ideologies and identities are reflected, enacted, re-enacted, negotiated, modified, reproduced, etc. For example, spatial proximization can construe the process of entities peripheral to the discourse space encroaching physically upon entities central to the discourse space (typically the speaker and addressee). That is, through ODC narrates its spatial distance with IDC, so that the addressee can identify with the events described by the speaker. Through temporal strategy, the ODC proximizes past events and the potential future to the present in order to explain the experience, lesson, or influence of past or future events on reality. Axiological proximization refers to the process through which the possibility of turning ideological conflict between ODC and IDC into practical conflict is reduced, and the ideological distance between the two sides is narrowed.

In terms of the specific text analyzed in this paper, the value of "a community of shared future for mankind" achieves temporal, spatial, and axiological unity in a number of ways. The first is time inheritance. "Building a community of shared future for mankind" includes the principle of equality and the sovereignty identified in the Peace Treaty of Westphalia over 360 years ago, the international humanitarian spirit of the Geneva Conventions more than 150 years ago, the four major purposes and seven principles included in the UN charter 70 years ago, the Five Principles of Peaceful Coexistence advocated at the Bandung Conference more than 60 years ago, and other series of principles that have evolved amidst the background of changes in international relations. These shared historical memories form the

\footnotetext{
9 The number represents the times of each strategy is used in the speech.
} 
foundation for building a community of shared future for mankind.

The second is spatial inclusion. Countries are different and the world is diverse; however, the shared situation and aspirations of all countries have linked them closely to form a common understanding and identity, which encourages all countries to shape a shared future. In the West, there is the saying "All for one, and one for all." In the East, there is "Appreciate the values of others as you would you own, and the world will become a harmonious whole. "The Koran includes the passage, "O mankind, indeed We have created you from male and female and made you peoples and tribes that you may know one another. Indeed,.”. In almost every society is the notion that difference is a driving force through which each nation and tribe can understand others, rather than a cause of conflict. As a representation of inclusiveness and the integration of human thought, "a community of shared future for mankind" points to the search for common ground while narrowing differences to form a new consensus among nations.

Third, the practical value in the proposition of a "Chinese solution" is an important starting point for the implementation of "a community of shared future for mankind." In response to the spread of extremism, terrorism, and populism in various countries, the value of a community of shared future for mankind aims to clear up the opposition of ideologies and values held by different countries and instead pursue a golden mean of human values. In terms of its specific content, "a community of shared future" is the sublimation of the ideas of a community of shared interests and shared responsibilities. In Xi's speech, these ideas initially focus on surroundings - the place for living, and later are often used among developing countries with emphasis on southern consciousness to reach the highest state of a community of human destiny, extending from the real world to virtual space - a cyberspace community of fate, from traditional fields expanding to a global commons - by upholding the principle of peace, sovereignty, inclusive benefits, and collaboration. It changes the deep sea, polar wastes, outer space, the Internet, and other frontiers into a new territory of cooperation rather than a place for contestation. The way to build a community of shared future for mankind is to seek the greatest common denominator of human values and shape the common values of mankind.

\section{CONCLUSION}

To explore the international values of President Xi's speech and the notion of "a community of shared future for mankind" from a cognitive linguistic perspective, this paper applies the deixis construal operation of proximization theory. This case study illustrates the purpose and strategy of international values of "a community of a shared future for mankind" and also demonstrates the general feasibility of proximization theory in critical discourse analysis and the specific explanatory power of its spatial-temporal-axiological (STA) model in value construction. However, the construction of international values through discourse is not an easy task, and might take long time to be accepted by addressees and the general public. Therefore, it is necessary to actively carry out a country-by-country comparative study on the construction of international values through discourse, so as to better understand the differences in national conditions and discourse systems. Studies like this represent an opportunity for more researchers in the field of linguistics to participate in discourse construction studies on international values. As China gradually moves to the center of the world stage, it will surely stand tall in the international community with a more prominent posture and a positive image.

\section{REFERENCES}

[1] Cap, P. (2006). Legitimization in Political Discourse: A Cross-Disciplinary Perspective on the Modern US War Rhetoric. Newcastle: Cambridge Scholars Press.

[2] Cap, P. (2008). Towards the Proximization Model of the Analysis of Legitimization in Political Discourse. Journal of Pragmatics, 40 (1), 17-41.

[3] Cap, P. (2010). Axiological Aspects of Proximization. Journal of Pragmatics, 42 (2), 392-407

[4] Cap, P. (2013). Proximization: The Pragmatics of Symbolic Distance Crossing. Amsterdam: John Benjamins.

[5] Cap, P. (2014). Applying Cognitive Pragmatics to Critical Discourse Studies: A Proximization Analysis of Three Public Space Discourses. Journal of Pragmatics, 70, 16-30.

[6] Cap, P. (2015). Crossing Symbolic Distances in Political Discourse Space: Evaluative Rhetoric within the Framework of Proximization. Critical Discourse Studies, 12 (3), 313-329.

[7] Chilton, P. (2004). Analyzing Political Discourse: Theory and Practice. London: Routledge.

[8] Chilton, P. (2005). Discourse Space Theory: Geometry, Brain and Shifting Viewpoints. Annual Review of Cognitive Linguistics, 3 (1), 78-116.

[9] Dunmire, P. (2011). Projecting the Future Through Political Discourse: The Case of the Bush Doctrine. Amsterdam: John Benjamins.

[10] Guo, X, (2017). Discourse Construction and Global Cognition of China's Global Governance Initiatives. Zhejiang Social Sciences, 33 (5), 121-126,159.

[11] Hart, C. (2010). Critical Discourse Analysis and Cognitive Science: New Perspectives on Immigration Discourse. Basingstoke: Palgrave Macmillan.

[12] Hart, C. (2011). Critical Discourse Studies in Context and Cognition. Amsterdam: John Benjamins.

[13] Hart, C. (2014). Discourse, Grammar and Ideology: Functional and Cognitive Perspectives. London: Bloomsbury.

[14] Huang, G. (2017). A Systemic Functional Linguistics Approach to a Political Speech-Analysis of President Xi Jinping's Speech at the General Debate of the 70th Session of the UN General Assembly. Foreign Language Research, 40 (3), 7-11.

[15] Talmy, L. (1988). Force Dynamics in Language and Cognition. Cognitive Science, 12 (1), 49-100. 
[16] Tian, H. (2013). A Qualitative-Research-Oriented CDA Mode. Foreign Languages and Their Teaching, 35 (4), 6-10.

[17] Wen, Q. (2017). Ideational, Interpersonal and Textual Metafunctions of the Personification of a Community of Shared Future for Mankind-Analysis of President Xi Jinping's Speech at the General Debate of the 70th Session of the UN General Assembly. Foreign Language Research, 40 (3), 1-6.

[18] Wen, X. (2011). Cognitive Linguistic Enterprise. Foreign Languages and Their Teaching, 33 (2), 1-5.

[19] Wu, J., J. Lin, and Y. Li. (2016). A New Method of Critical Discourse Analysis- Proximization. Journal of Foreign Languages, $39(5), 75-82$.

[20] Xin, B. and X. Gao. (2013). The Goal, Methodology, Problems and Recent Trends of CDA. Foreign Languages and Their Teaching, 35 (4), 1-5, 16.

[21] Xi, J. (2017, October18) Report to the 19th national congress of the Communist Party of China. The Xinhuanet website. Retrieved May 13,2019,from http://www.xinhuanet.com/english/special/2017-11/03/c_136725942.htm.

[22] Xi, J. (2017, January 18). Work Together to Build a Community of Shared Future for Mankind — President Xi Jinping's Speech at the United Nations Office at Geneva. The Xinhuanet website. Retrieved April 17, 2019, from http://www.xinhuanet.com//english/2017-01/19/c_135994707.htm.

[23] Zhang, Hui. and L. Jiang. (2008). Integration of Cognitive Linguistics and Critical Discourse Analysis. Foreign Language Research, 31 (5), 12-19.

[24] Zhang, Hong. (2017). China's Country Image Projection from the Indexicality Principle of the Sociocultural Linguistic Approach-Analysis of Xi Jinping's Speech at UN. Foreign Language Research, 40 (3),17-21.

[25] Zhang, T. and B. Guo. (2016). Discursive Strategies and Construal Operations in CDA. Foreign Language Education, 37 (6): $17-22$

[26] Zhou Y. (2018). On the Assurance of the Right of China's International Discourse in the Perspective of Xi Jinping's Theory of the Community of Human Destiny. Journal of Yunnan Minzu University (Social Sciences), 35 (2), 22-30.

Yunyou Wang, born on 1st, December, 1991, is studying in Southwest University of China as a PHD candidate, majoring in English Language and linguistics, and focusing on the research of cognitive linguistics. In 2013, she graduated from the University of Electronic Science and Technology of China (UESTC) as an English major with a bachelor's degree and then got the master's degree of interpreting and translation in Chongqing University in 2015. Later on, she was working in China Mobile as a secretary for one year, and then successfully enrolled in Southwest University as a PHD candidate. 